\title{
PENDEKATAN INTEGRATED PERFORMANCE MEASUREMENT SYSTEMS (IPMS) UNTUK MENGUKUR KINERJA SEKOLAH KEJURUAN
}

\author{
Mokhammad Arif Hidayatulloh \\ e-mail : arifhidayatulloh1412@gmail.com \\ Teknik Industri, Fakultas Teknik \\ Universitas Maarif Hasyim Latif, Sidoarjo, Indonesia
}

\begin{abstract}
ABSTRAK
Sekolah Menengah Kejuruan Yayasan Pendidikan Maarif 1 Kecamatan Taman Kabupaten Sidoarjo adalah sekolah menengah kejuruan memiliki jurusan Teknik antara lain yakni instalasi tenaga listrik, permesinan, komputer jaringan, elektronika industri, dan pengelasan. permasalahan yang dihadapi guru dalam memenuhi kriteria pembelajaran sesuai standar nasional adalah beban kerja yang lumayan berat sehingga terkadang bisa pulang hingga malam diluar jam kerja. Tujuan membuat penelitian ini adalah menentukan KPI yang bisa digunakan untuk mengukur kinerja sekolah secara menyeluruh dan mengukur kinerja sekolah berdasarkan metode (IPMS). Metode IPMS dinilai mampu untuk meningkatkan kinerja sekolah secara menyeluruh. Dari hasil penelitian yang dilakukan, diperoleh 8 sub kriteria dengan $21 \mathrm{KPI}$. Untuk hasil 8 sub kriteria ketercapaian kinerja dengan nilai kurikulum 2,114, proses pembelajaran 1,544, kompetensi lulusan 0,549, penilaian 0,846, pendidik dan tenaga kependidikan 0,770, sarana dan prasarana 0,6 , pengelolaan 0,456 , pembiayaan 0,717 , berdasarkan hasil pembobotan dan scoring maka didapatkan kinerja SMK YPM 1 Taman sebesar 7,596 maka dapat dikategorikan kinerja SMK YPM 1 Taman cukup baik.
\end{abstract}

Kata kunci: $I P M S, K P I$, Pengukuran Kinerja

\section{PENDAHULUAN}

Pendidikan merupakan elemen terpenting dalam kemajuan suatu negara. Terlebih dengan pesatnya kemajuan ekonomi dan teknologi saat ini tuntutan akan kebutuhan pendidikan menjadi sangat penting. Lembaga pendidikan yang berpengaruh besar adalah sekolah. Sekolah merupakan organisasi yang memiliki tugas utama memberikan layanan pendidikan bermutu kepada masyarakat untuk memenuhi tuntutan dan kewajiban negara untuk menyediakan pendidikan yang berkualitas.

Arus globalisasi menuntut pentingnya pembinaan sumber daya manusia berkualitas pada semua sektor supaya memiliki kemampuan untuk bersaing dengan negara-negara lainnya. Salah satu langkah yang diambil oleh pemerintah dalam pemenuhan SDM level menengah yang berkualitas adalah melalui pembinaan pendidikan kejuruan. Berdasarkan UU No 20 Thn 2003, tentang pendidikan menengah yang mempersiapkan siswa-siswi terutama untuk bekerja dalam bidang tertentu. Oleh sebab itu, fokus dari pendidikan kejuruan menurut pendapat Djojonegoro (1998) menekankan pada penguatan pengetahuan, terampil, sikap dan nilai yang diinginkan oleh pekerjaan. Sehingga output yang diharapkan adalah tercetak generasi lulusan yang memiliki skill dan siap kerja pada bidang tertentu yang digelutinya.

Dilansir dari Badan Pusat Statistik yang dikutip dari media CNN Indonesia mencatat bahwa jumlah pengangguran naik menjadi 50.000 (lima puluh ribu) orang per Agustus 2019. Oleh sebab itu instansi sebagai suatu lembaga penyedia layanan pendidikan dapat berperan untuk mengurangi bertambahnya angka pengangguran. Berkaitan dengan hal ini, sekolah dapat mengarahkan manajemennya pada kinerja yang mengacu peningkatan kualitas yang berkelanjutan. Saat ini pengukuran kinerja sekolah dilakukan oleh badan akreditasi sekolah nasional (BASNAS). Dimana tugas badan tersebut adalah mengawasi dan mengendalikan mutu sekolah namun hanya pada lingkup evaluasi eksternal saja. Pihak sekolah juga perlu melakukan evaluasi internal untuk mengukur kinerja sekolah.

Melihat urgensitas sekolah menengah kejuruan dalam mencetak lulusan dengan skill siap bekerja dalam bidangnya, pada tugas akhir ini peneliti mengambil studi kasus disebuah sekolah menengah kejuruan swasta yaitu Sekolah Menengah Kejuruan Yayasan Pendidikan Maarif 1 Taman Sidoarjo. Seiring dengan semakin kompetitifnya persaingan di dunia pendidikan, maka perlu dilakukan pengukuran kinerja di Sekolah Menengah Kejuruan YPM 1 untuk mengetahui dan menganalisa kinerja institusi tersebut agar dapat meningkatkan kualitas secara 
terus menerus. Baik itu kualitas dari murid maupun guru serta pegawai yang ada di lingkungan sekolah. Berbeda dengan organisasi profit yang mengutamakan keuntungan, organisasi pendidikan tentu lebih mengutamakan bagaimana cara agar mutu pendidikan meningkat sehingga dapat menghasilkan lulusan dengan prestasi terbaik.

Sekolah Menengah Kejuaruan Yayasan Pendidikan Maarif 1 Taman Sidoarjo ini didirikan pada tanggal 20 Mei 1980. Pendiri Sekolah Menengah Kejuruan Yayasan Pendidikan Maarif 1 Taman Sidoarjo secara operasional dilakukan oleh tim yang dibentuk yayasan pendidikan dan sosial Maarif Taman Sepanjang Sidoarjo, dengan ketua almarhum Drs. H. A. Wachid Syamsudin, Ir. Drs. H. Soekarmin, almarhum H. Achmad Buchori Santoso, sekretaris Achmad Farich, S.T.,M.Pd., serta anggota Prof. Dr. Muchlas Samani, M.Pd. Dan Drs. Mohammad Yadi. Pengembangan program kejuruan hingga saat ini terdiri dari 5 (lima) jurusan, yaitu elektronika industri, instalasi tenaga listrik, permesinan, pengelasan dan komputer jaringan. Adapun visi dari Sekolah Menengah Kejuruan Yayasan Pendidikan Maarif 1 Taman Sidoarjo adalah terwujudnya lembaga pendidikan kejuaruan yang berkualitas, bernafaskan islam menurut paham Ahlussunnah Wal Jamaah dan berwawasan kebangsaan. Dalam mewujudkan visi tersebut, tentu ada misi yang dijalankan yaitu mengembangkan studi keislaman serta mengembangkan ilmu pengetahuan dan teknologi secara komprehensif dan professional yang mampu mencetak insan muslim yang memiliki integritas keilmuan, berakhlak mulia dan berdaya saing.

Dalam mewujudkan visi dan misi tersebut menurut penuturan Bapak Amir sebagai salah satu pengajar di Sekolah Menengah Kejuruan Yayasan Pendidikan Maarif 1 Taman Sidoarjo, pada tahun 2018 prestasi ujian nasional yang diraih masih berada pada peringkat 20 (dua puluh) se-SMK Sidoarjo. Permasalahan lain yang dihadapi menurut Bapak Amir dalam memenuhi kriteria pembelajaran sesuai standar nasional adalah beban kerja yang lumayan berat sehingga terkadang bisa pulang hingga malam diluar jam kerja. Dari permasalahan diatas maka perlu dilakukan pengukuran kinerja institusi Sekolah Menengah Kejuruan Yayasan Pendidikan Maarif 1 Taman Sidoarjo. Adapun salah satu metode yang digunakan untuk melakukan pengukuran kinerja adalah Integrated Performance Measurement Systems (IPMS). Pengukuran kinerja tersebut akan menghasilkan indikator-indikator yang menjadi prioritas utama untuk ditingkatkan oleh pihak institusi sehingga dapat digunakan oleh lembaga pendidikan Sekolah Menengah Kejuruan Yayasan Pendidikan Maarif 1 Taman Sidoarjo untuk mengambil keputusan terbaik demi terciptanya tujuan yang lebih baik dimasa yang akan datang. Maka dari itu, peneliti tertarik untuk melakukan penelian mengenai pengukuran kinerja melalui metode Integrated Performance Measurement Systems (IPMS) di Sekolah Menengah Kejuruan Yayasan Pendidikan Maarif 1 Taman. (Aziza, Suwignyo, Makki, 2019).

\section{METODE PENELITIAN}

Proses penelitian dapat berjalan lancar dan sesuai dengan tujuan peneliti, maka dibuat suatu alur atau langkah-langkah dalam kegiatan penelitian. Untuk tahapan-tahapan penelitian dapat dilihat pada Gambar 1. Dalam pemilihan sub kriteria dan KPI dilakukan melalui kuesioner dan wawancara sedangkan pembobotan subkriteria dilakukan berdasarkan hasil dari perbandingan yang dilakukan oleh para stakeholder. Untuk data kinerja sekolah berasal dari dokumentasi sekolah mulai dari periode semester gasal tahun pembelajaran $2019-2020$.

\section{Integrated Performance Measurement Systems (IPMS)}

IPMS adalah sistem yang dinamis dan seimbang, yang memberikan pandangan holistik dari penggunaan berbagai perspektif dan pengukuran.

Integrated Performance Measurement Syistem (IPMS) merupakan metode pengukuran kinerja yang terintegrasi yaitu mengukur kinerja suatu perusahaan yang dilakukan secara top-down dengan memperhatikan kebutuhan dari setiap stakeholders-nya dan tetap memonitor posisi perusahaan terhadap pesaingnya.

Tujuan dari model IPMS, agar sistem pengukuran kinerja lebih akurat, terintegrasi, efektif dan efisien. Berbeda dengan model lainnya, model ini menjadikan keinginan stakeholder menjadi titik awal dalam melakukan perancangan sistem pengukuran kinerjanya. Peranan stakeholder tidak hanya pemegang saham, melainkan beberapa pihak yang memilki kepentingan atau dipentingkan oleh organisasi seperti konsumen, karyawan, pemasok dan lainlain. Faktor orientasi organisasi yang utama adalah ada atau tidaknya visi, misi, strategi, jumlah stakeholder yang mempengaruhi dan jumlah bahkan jenis produk yang dimiliki yaitu faktor yang menjadi landasan untuk mengkomparasikan faktor kondisi objektif dengan model IPMS.

\section{Langkah-Langkah Penyelesaian Dengan Metode AHP Dengan Software Expert Choice 11 Dan Metode OMAX}

1. Pembobotan Kinerja Organisasi Sekolah 
Pembobotan KPI untuk mengetahui tingkat kepentingan atau pengaruh masing-masing indikator terhadap kinerja sekolah secara menyeluruh. Untuk kinerja sekolah ini, maka perlu disusun 9 matriks perbandingan kinerja untuk masing-masing subsistem kriteria sesuai dengan hierarki kinerja sekolah. Hasil pengisian matriks perbandingan dibawah ini, kemudian diolah dengan software Expert choice 11 untuk mendapatkan hasil pembobotan.

\begin{tabular}{|c|c|c|c|c|c|c|c|c|}
\hline Indikator Kine rja & Kurikulum & $\begin{array}{c}\text { Prowen } \\
\text { Pembelajaran }\end{array}$ & $\begin{array}{l}\text { Kompetenut } \\
\text { Luhsan }\end{array}$ & Pentaian & \begin{tabular}{|c|c|} 
Pendidik dan \\
Tenayma \\
Kependidik
\end{tabular} & $\begin{array}{l}\text { Sarana dan } \\
\text { Prasarana }\end{array}$ & Penurolanan & Pembiayan \\
\hline Kurikulum & & 2 & 3 & 3 & 1 & 3 & 3 & 2 \\
\hline Proses Pembelajaran & & & 4 & 3 & 4 & 2 & 3 & 2 \\
\hline Ko mpetene Luluwan & & & & 4 & 3 & 3 & 2 & 2 \\
\hline Penilaian & & & & & 2 & 2 & 3 & 1 \\
\hline Pendidik dan Tera fa Kependidik & & & & & & 2 & 2 & 1 \\
\hline Sarana dan Pra sarana & & & & & & & 1 & 1 \\
\hline Pengeo la an & & & & & & & & 1 \\
\hline Pembiayaan & & & & & & & & \\
\hline
\end{tabular}

2. Hasil Pembobotan Kinerja

Hasil pembobotan kelompok kinerja organisasi sekolah masing-masing KPI terhadap kinerja sekolah secara keseluruhan. Hasil pembobotan tertinggi pada aspek proses pembelajaran. Ini menunjukkan bahwa proses pembelajaran memiliki tingkat kepentingan yang menentukan performansi sekolah

Tabel 2 Hasil Pembobotan Overall Performance

\begin{tabular}{|l|c|}
\hline \multicolumn{1}{|c|}{ Kelompok Objective } & Bobot (\%) \\
\hline Kurikulum & 23,1 \\
\hline Proses pembelajaran & 23,3 \\
\hline Kopetensi lulusan & 15,7 \\
\hline Penilaian & 9,4 \\
\hline $\begin{array}{l}\text { Pendidik dan tenaga } \\
\text { kependidikan }\end{array}$ & 8,9 \\
\hline Sarana dan prasarana & 6 \\
\hline Pengelolaan & 5,7 \\
\hline Pembiayaan & 7,8 \\
\hline Jumlah & 100 \\
\hline Inconsistency ratio & $0,09 /$ konsisten \\
\hline
\end{tabular}

3. Analisa pengukuran kinerja sekolah

menggunakan scoring system

Dalam merancang sistem pengukuran kinerja sekolah perlu adanya scoring system yang bertujuan untuk mengetahui seberapa besar nilai pencapaian kinerja sekolah dalam periode tertentu. Scoring system ini dilakukan dengan bantuan software excell yang mengaplikasikan sistem penilaian OMAX (Objective matrix).

Setelah dilakukan scoring system untuk masing-masing KPI serta semua performance sekolah dengan menggunakan $O M A X$, dimana akan diketahui nilai capaian kinerja dari target yang telah ditentukan. Maka langkah selanjutnya adalah membuat traffic light system yang bertujuan untuk mengetahui apakah score dari KPI memerlukan perbaikan atau tidak berdasarkan warna indikator.

\section{Traffic Light System}

Dalam traffic light system, ada 3 (tiga) warna yang digunakan untuk mengidentifikasi apakah suatu KPI memerlukan perbaikan atau tidak yaitu antara la

\section{Tabel 4 Traffic Light System}

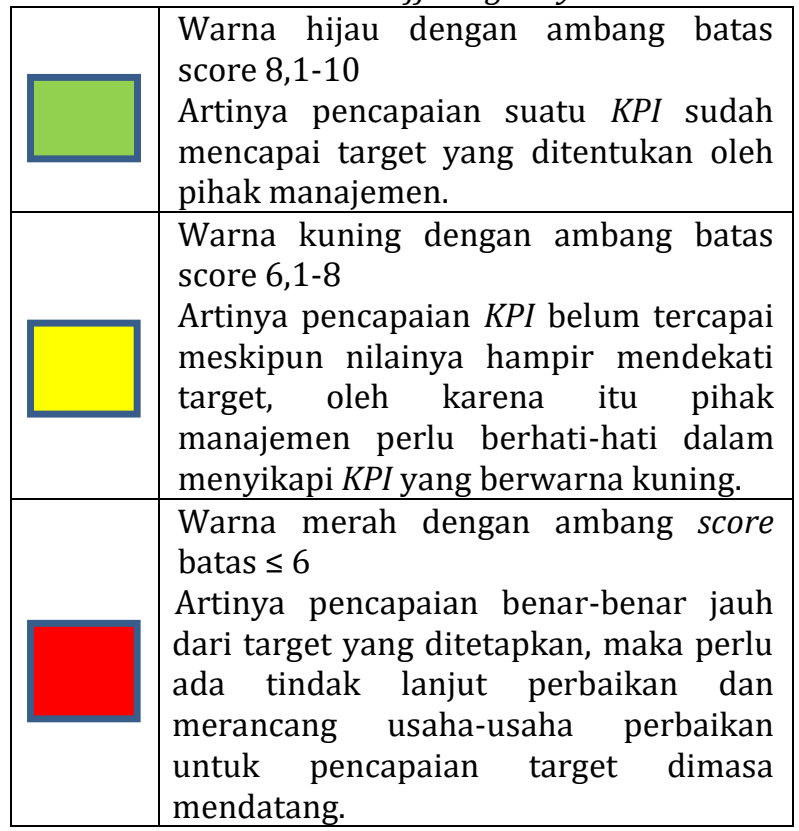

Sumber: James L.Riggs, 1986 
Tabel 3 Pengukuran Kinerja Sekolah dengan $O M A X$

\begin{tabular}{|c|c|c|c|c|c|c|c|c|c|c|}
\hline \multicolumn{10}{|c|}{ PENGUKURAN KINERJA SEKOLAH DENGAN PENILAIAN OMAX } & \\
\hline \multicolumn{3}{|c|}{ KURIKULUM } & \multicolumn{5}{|c|}{ PROSES PEMBELAJARAN } & \multicolumn{2}{|c|}{ KOPETENSI LULUSAN } & \\
\hline KPI 1 & KPI 2 & $\mathrm{KPI} 3$ & $\mathrm{KPI} 4$ & KPI 5 & KPI 6 & KPI 7 & KPI 8 & KPI 9 & KPI 10 & \\
\hline 100 & 90 & 100 & 87.43 & 0.22 & 87.04 & 0.07 & 69.86 & 8.48 & 31.3 & Pencapaiar \\
\hline 100 & 100 & 100 & 100 & 0.25 & 100 & & & & & \\
\hline 96.42857 & 94.28571 & 99. 28571 & $|97.85714|$ & 0.228571429 & 98. 14286 & 0.087071 & 90 & 9.857143 & 77.142866 & \\
\hline 93.36735 & 88.43537 & 98.43537 & 95.78231 & 0.208156463 & 96.31293 & 0.075942 & 89.90476 & 9.734694 & 74.21769 & \\
\hline 85.3863 & 79.61127 & 91.03984 & 88.05151 & 0.184538873 & 88,64917 & 0.065748 & 83.44218 & 8.98688 & 67.66278 & \\
\hline 83.90254 & 73.95252 & 90.8913 & 86.90129 & 0.166319034 & 87.69929 & 0.05757 & 84.09329 & 8.988755 & 65.13953 & \\
\hline 69.91878 & 61.6271 & 75.74275 & 72.41774 & 0.138599195 & 73.08274 & 0.047975 & 70.07775 & 7.490629 & 54.28294 & \\
\hline 70.93503 & 57.30168 & 78.5942 & 73.93419 & 0.122279356 & 74.86619 & 0.04008 & 73.6622 & 7.792503 & 53.42635 & \\
\hline 75 & 60 & 95 & 85 & 0.1 & 87 & 0.0005 & 90 & 9 & 60 & \\
\hline 75 & 53.33933 & 93.33393 & 83.39333 & 0.085666667 & 85. 39393 & 0.009167 & 89.33933 & 9 & 56.66667 & \\
\hline 37.5 & 26.66667 & 46.66667 & 41.66667 & 0.042833333 & 42.66667 & 0.004583 & 44.66667 & 4.5 & 28.33333 & \\
\hline 75 & 40 & 90 & 80 & 0.057 & 82 & 0.0035 & sg & 9 & so & \\
\hline & & & & & & & & & & \\
\hline 10 & 8 & 10 & 6 & 9 & 6 & 7 & 5 & 6 & 1 & SCORE \\
\hline 42.9 & 42.9 & 14.3 & 26.1 & 22.2 & 19.2 & 14.1 & 18.5 & 50 & 50 & WEIGHT \\
\hline 429 & 343.2 & 143 & 156.6 & 199.8 & 115.2 & 98.7 & 92.5 & 300 & so & VALUE \\
\hline \multirow{2}{*}{\multicolumn{2}{|c|}{ INDEKS KURIKULUM }} & & \multirow{2}{*}{\multicolumn{3}{|c|}{ INDEKS PROSES PEMBELAJARAN }} & & & \multirow{2}{*}{\multicolumn{2}{|c|}{ INDEKS KOPETENSI }} & \\
\hline & & & & & & & & & & \\
\hline & & 915.2 & & & & & 662.8 & & 350 & \\
\hline
\end{tabular}

\begin{tabular}{|c|c|c|c|c|c|c|c|c|c|c|c|}
\hline \multicolumn{12}{|c|}{ PENGUKURAN KINERJA SEKOLAH DENGAN PENILAIAN OMAX (LANJUTAN) } \\
\hline \multicolumn{2}{|c|}{ PENILAIAN } & \multicolumn{3}{|c|}{ PENDIDIK \& TENAGA KEPENDIDIKAN } & \multicolumn{2}{|c|}{ SARPRAS } & \multicolumn{2}{|c|}{ PENGELOLAAAN } & \multicolumn{2}{|c|}{ PEMBIAYAAN } & \multirow[b]{3}{*}{ Pencapaian } \\
\hline KPI 11 & KPI 12 & KPI 13 & KPI 14 & KPI 15 & KPI 16 & KPI 17 & KPI 18 & KPI 19 & KPI 20 & KPI 21 & \\
\hline 1.63 & 100 & 58 & 0.68 & 81.5 & 42 & 11 & 81.31 & 203.72 & 105.86 & 137.61 & \\
\hline & & & & & & & & & & & \\
\hline 1.7 & 100 & 59 & 0.7 & 85 & 42 & 11 & 85 & 204 & 106 & 138 & 10 \\
\hline 1.671429 & 100 & 59 & 0.692857 & 84.71428571 & 42 & 11 & 84.28571 & 203.8571 & 105.1429 & 132.571429 & 9 \\
\hline 1.646939 & 100 & 59 & 0.684354 & 83.85034014 & 42 & 11 & 83.43537 & 203.5918 & 104,4082 & 127.918367 & 8 \\
\hline 1.518805 & 92.85714 & 59 & 0.631827 & 77.49076774 & 42 & 11 & 77.11127 & \begin{tabular}{||c|}
$\mid 188.9359$ \\
\end{tabular} & 96.63557 & 116.787172 & 7 \\
\hline 1.516118 & 93.87755 & 59 & 0.62728 & 76.42065806 & 42 & 11 & 76.80966 & 190.5165 & 97.1162 & 114.389005 & 6 \\
\hline 1.263432 & 78.23129 & 49.16667 & 0.522734 & 63.68388172 & 42 & 11 & 64.00805 & 158.7637 & 80.93017 & 95.3241705 & \\
\hline 1.310746 & 82.58503 & 51.13333 & 0.538187 & 64.94710537 & 42 & 11 & 72.00403 & 180.8819 & 90.46508 & 97.6620852 & \\
\hline 1.5 & 100 & \begin{tabular}{|r|}
59 \\
\end{tabular} & 0.65 & 83 & 42 & 11 & 80 & 203 & \begin{tabular}{|l|}
100 \\
\end{tabular} & 100 & \\
\hline 1.5 & 100 & 59 & 0.633333 & 78.66666667 & 42 & 11 & 78.33333 & 202 & 100 & 100 & \\
\hline 0.75 & 50 & 59 & 0.316667 & 39.33333333 & 42 & 11 & 39.16667 & 101 & 50 & 50 & \\
\hline 1.5 & 100 & 59 & 0.6 & 70 & 42 & 11 & 75 & 200 & 100 & 100 & \\
\hline & & & & & & & & & & & \\
\hline 8 & 10 & 10 & 8 & 8 & 10 & 10 & 8 & 8 & 9 & 10 & SCORE \\
\hline 50 & 50 & 32.7 & 41.3 & 26 & 50 & 50 & 66.7 & 33.3 & 80 & 20 & WEIGHT \\
\hline 400 & 500 & 327 & 330.4 & 208 & 500 & 500 & 533.6 & 266.4 & 720 & 200 & VALUE \\
\hline & & & & & & & & & & & \\
\hline \multicolumn{2}{|c|}{ INDEKS PENILAIAN } & \multicolumn{3}{|c|}{ INDEKS PENDIDIK DAN } & \multicolumn{2}{|c|}{ INDEKS SARPRAS } & INDEKS & & INDEKS & & \\
\hline & & TENAGA KE & EPENDIDIK, & & & & \multicolumn{2}{|c|}{ PENGELOLAAN } & \multicolumn{2}{|c|}{ PEMBIAYAAN } & \\
\hline & 900 & & & 865.4 & & 1000 & & 800 & & 920 & \\
\hline
\end{tabular}

Tabel 5 Traffic Light Pengukuran Kinerja

\begin{tabular}{|c|c|c|c|c|c|c|c|c|c|c|}
\hline \multicolumn{10}{|c|}{ PENGUKURAN KINERJA SEKOLAH DENGAN PENILAIAN OMAX } & \\
\hline \multicolumn{3}{|c|}{ KURIKULUM } & \multicolumn{5}{|c|}{ PROSES PEMBELAJARAN } & \multicolumn{2}{|c|}{ KOPETENSI LULUSAN } & \\
\hline KPI 1 & KPI 2 & KPI 3 & KPI 4 & KPI 5 & KPI 6 & $\mathrm{KPI} 7$ & KPI 8 & KPI 9 & KPI 10 & \\
\hline 100 & 90 & 100 & 87.43 & 0.22 & 87.04 & 0.07 & 69.86 & 8.48 & 31.3 & Pencapaian \\
\hline & & & & & & & & & & \\
\hline 100 & 100 & 100 & 100 & 0.25 & 100 & 0.1 & 90 & 10 & 80 & 10 \\
\hline 96.42857 & 94.28571 & 99.28571 & 97.85714 & 0.228571429 & 98.14286 & 0.087071 & 90 & 9.857143 & 77.14286 & 9 \\
\hline 93.36735 & 88.43537 & 98.43537 & 95.78231 & 0.208156463 & 96.31293 & 0.075942 & 89.90476 & 9.734694 & 74.21769 & 8 \\
\hline 85.3863 & 79.61127 & 91.03984 & 88.05151 & 0.184538873 & 88.64917 & 0.065748 & 83.44218 & 8.98688 & 67.66278 & 7 \\
\hline 83.90254 & 73.95252 & 90.8913 & 86.90129 & 0.166319034 & 87.69929 & 0.05757 & 84.09329 & 8.988755 & 65.13953. & \\
\hline 69.91878 & 61.6271 & 75.74275 & 72.41774 & 0.138599195 & 73.08274 & 0.047975 & 70.07775 & 7.490629 & 54.28294 & 5 \\
\hline 70.93503 & 57.30168 & 78.5942 & 73.93419 & 0.122279356 & 74.86619 & 0.04008 & 73.6622 & 7.792503 & 53.42635 & \\
\hline 75 & 60 & 95 & 85 & 0.1 & 87 & 0.0095 & 90 & 9 & 60 & \\
\hline 75 & 53.33333 & 93.33333 & 83.33333 & 0.085666667 & 85.33333 & 0.009167 & 89.33333 & 9 & 56.66667 & 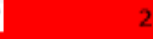 \\
\hline 37.5 & 26.66667 & 46.66667 & 41.66667 & 0.042833333 & 42.66667 & 0.004583 & 44.66667 & 4.5 & 28.33333 & \\
\hline 75 & 40 & 90 & 80 & 0.057 & 82 & 0.0085 & 88 & 9 & 50 & \\
\hline & & & & & & & & & & \\
\hline 10 & 8 & 10 & 6 & 9 & 6 & 7 & 5 & 6 & 1 & SCORE \\
\hline 42.9 & 42.9 & 14.3 & 26.1 & 22.2 & 19.2 & 14.1 & 18.5 & 50 & 50 & WEIGHT \\
\hline 429 & 343.2 & 143 & 156.6 & 199.8 & 115.2 & 98.7 & 92.5 & 300 & 50 & VALUE \\
\hline \multicolumn{2}{|c|}{ INDEKS KURIKULUM } & & \multicolumn{3}{|c|}{ INDEKS PROSES PEMBELAJARAN } & & & \multicolumn{2}{|c|}{ INDEKS KOPETENSI } & \\
\hline & & & & & & & & LULUSAN & & \\
\hline & & 915.2 & & & & & 662.8 & & 350 & \\
\hline
\end{tabular}




\begin{tabular}{|c|c|c|c|c|c|c|c|c|c|c|c|}
\hline \multicolumn{12}{|c|}{ PENGUKURAN KINERJA SEKOLAH DENGAN PENILAIAN OMAX (LANJUTAN) } \\
\hline \multicolumn{2}{|c|}{ PENILAIAN } & \multicolumn{3}{|c|}{$\begin{array}{l}\text { PENGUKURAN KINERJA SEK } \\
\text { PENDIOIK \& TENAGA KEPENDIOIKAN }\end{array}$} & \multicolumn{2}{|c|}{ SARPRAS } & \multicolumn{2}{|c|}{ PENGELOLAAN } & \multicolumn{2}{|c|}{ PEMBIAYAAN } & \multirow[b]{3}{*}{ Pencapalan } \\
\hline KPI $11 \quad$ K & KPI 12 & KPI 13 & |KPI 14 & KPI 15 & KPI 16 & KPI 17 & KPI 18 & |KPI 19 & KPI 20 & KPI 21 & \\
\hline 1.63 & 100 & 58 & 0.68 & 81.5 & 42 & 11 & 81.31 & 203.72 & 105.86 & 137.61 & \\
\hline & & & & & & & & & & & \\
\hline 1.7 & 100 & 59 & 0.7 & 85 & 42 & 11 & 85 & 204 & 106 & 138 & 10 \\
\hline 1.671429 & 100 & 59 & 0.692857 & 84.71428571 & 42 & 11 & 84.28571 & 203.8571 & 105.1429 & 132.571429 & 9 \\
\hline 1.646939 & 100 & 59 & 0.684354 & 83.85034014 & 42 & 11 & 83.43537 & 203.5918 & 104.4082 & 127.918367 & 8 \\
\hline 1.518805 & 92.85714 & 59 & 0.631827 & 77.49076774 & 42 & 11 & 77.11127 & 188.9359 & 96.63557 & $\mid 116.787172$ & 7 \\
\hline 1.516118 & 93.87755 & 59 & 0.62728 & 76.42065806 & 42 & 11 & 76.80966 & 190.5165 & 97.1162 & 114.389005 & 6 \\
\hline 1.263432 & 78.23129 & 49.16667 & 0.522734 & 63.68388172 & 42 & 11 & 64.00805 & 158.7637 & 80.93017 & 95.3241705 & \\
\hline 1.310746 & $|82.58503|$ & $|51.13333|$ & 0.538187 & 64.94710537 & 42 & 11 & 72.00403 & 180.8819 & 90,46508 & 97.6620852 & \\
\hline 1.5 & \begin{tabular}{|l|}
100 \\
\end{tabular} & \begin{tabular}{|r|} 
\\
59
\end{tabular} & 0.65 & 83 & 42 & 11 & 80 & | 203 & 100 & \begin{tabular}{|l|}
100 \\
\end{tabular} & \\
\hline 1.5 & 100 & 59 & 0.633333 & 78.66666667 & 42 & 11 & 78.33333 & 202 & 100 & 100 & \\
\hline 0.75 & 50 & 59 & 0.316667 & 39.33333333 & 42 & 11 & 39.16667 & 101 & 50 & 50 & \\
\hline 1.5 & 100 & 59 & 0.6 & 70 & 42 & 11 & 75 & 200 & 100 & 100 & \\
\hline & & & & & & & & & & & \\
\hline 8 & 10 & 10 & 8 & 8 & 10 & 10 & 8 & 8 & 9 & 10 & SCORE \\
\hline 50 & 50 & 32.7 & 41.3 & 26 & 50 & 50 & 66.7 & 33.3 & 80 & 20 & WEIGHT \\
\hline 400 & 500 & 327 & 330.4 & 208 & 500 & 500 & 533.6 & 266.4 & 720 & 200 & VALUE \\
\hline \multicolumn{2}{|c|}{ INDEKS PENILAIAN } & \multicolumn{2}{|c|}{ INDEKS PENDIDIK DAN } & & \multicolumn{2}{|c|}{ INDEKS SARPRAS } & INDEKS & & INDEKS & & \\
\hline & & TENAGA KE & KEPENDIDIK & KAN & & & \multicolumn{2}{|c|}{ PENGELOLAAN } & \multicolumn{2}{|c|}{ PEMBIAYAAN } & \\
\hline & 900 & & & 865.4 & & 1000 & & 800 & & 920 & \\
\hline
\end{tabular}

\section{HASIL DAN PEMBAHASAN}

Hasil Objectives dan Spesifikasi KPI berdasarkan hasil requirement stakeholder yang berjumlahkan 8 requirement, penggolongan dimensi berjumlahkan
8 sub kriteria yang telah menghasilkan 21 KPI yang terdiri dari 3 KPI kurikulum, $5 \mathrm{KPI}$ proses pembelajaran, 2 KPI kopetensi lulusan, 2 KPI penilaian, 3 pendidik dan tenaga kependidikan, 2 KPI sarana dan prasarana, 2 KPI pengelolaan, $2 \mathrm{KPI}$ pembiayaan.

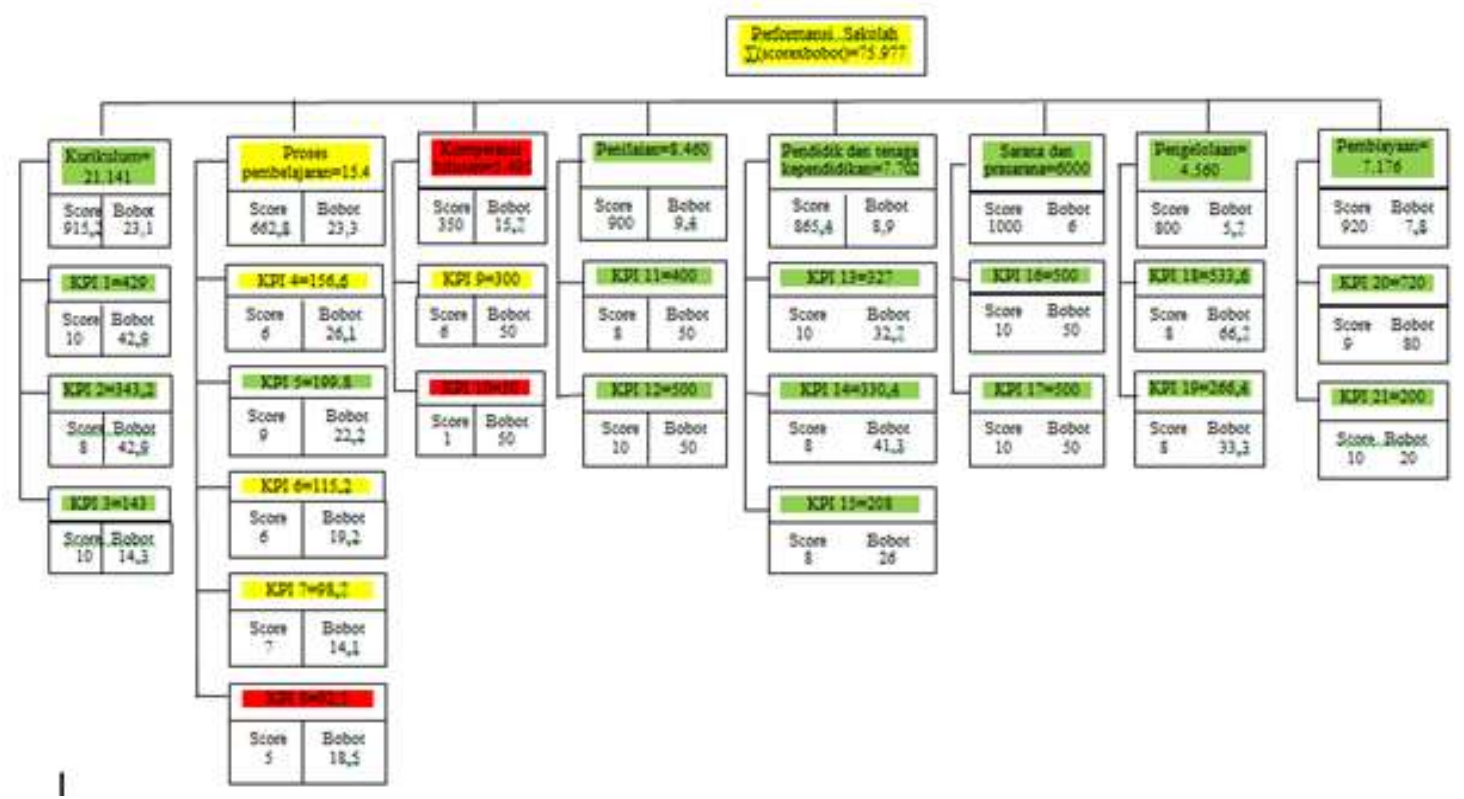

Gambar 2 Struktur Hierarki Hasil Pembobotan Kinerja Sekolah

Hasil pencapaian kinerja dengan menggunakan metode omax untuk masing-masing sub kriteria sebagai berikut:

1. Sub kriteria kurikulum: memiliki skor kinerja 9,152, dengan warna indikator hijau, artinya skor kinerja yang dicapai organisasi sangat memuaskan.

2. Sub kriteria proses pembelajaran: memiliki skor kinerja 6,628, dengan warna indikator kuning, artinya kinerja sub kriteria ini belum memuaskan karena pencapaian kinerja belum memenuhi target yang telah ditetapkan.
3. Sub kriteria kompetensi lulusan: memiliki skor kinerja 3,5, dengan warna indikator merah, artinya kinerja untuk sub kriteria ini sangat rendah. Hal ini menunjukkan bahwa KPI untuk sub kriteria ini pencapaian realistisnya jauh dari target yang telah ditentukan.

4. Sub kriteria penilaian: mempunyai skor kinerja sebesar 9, dengan warna indikator hijau, artinya kinerja untuk sub kriteria pencapaian kinerjanya sesuai dengan target yang ditentukan. 
5. Sub kriteria Pendidik dan tenaga kependidikan: memiliki skor kinerja 8,654, dengan warna indikator hijau, artinya skor kinerja yang dicapai sangat memuaskan.

6. Sub kriteria Sarana dan prasarana: mempunyai skor kinerja sebesar 10, dengan warna indikator hijau, artinya kinerja untuk sub kriteria pencapaian kinerjanya sesuai dengan target yang ditentukan.

7. Sub kriteria Pengelolaan: memiliki skor kinerja 8, dengan warna indikator hijau, artinya skor kinerja yang dicapai sangat memuaskan.

8. Sub kriteria Pembiayaan: memiliki skor kinerja 9,2, dengan warna indikator hijau, artinya skor kinerja yang dicapai sangat memuaskan.

\section{PENUTUP}

Penelitian ini bertujuan untuk mengetahui tingkat kepentingan sub kriteria dalam pengukuran kinerja sekolah serta untuk mengetahui kinerja sekolah SMK YPM 1 Taman. Dari hasil penelitian diketahui hasil pembobotan dan scoring maka didapatkan kinerja SMK YPM 1 Taman sebesar 7,596 maka dapat dikategorikan kinerja SMK YPM 1 Taman cukup baik. Dari hasil penelitian yang telah dilakukan dapat dijadikan sebagai bahan referensi bagi sekolah dalam proses meningkatkan kinerja organisasi. Peneltian ini juga bisa digunakan sebagai bukti dokumentasi akan adanya penilaian evaluasi untuk meningkatkan kinerja sekolah secara menyeluruh. Sedangkan untuk peneliti selanjutnya dapat dilakukan pengembangan metode atau kolaborasi dengan metode pengukuran kinerja yang lainnya untuk dijadikan perbandingan dan pemilihan metode yang sesuai dengan kebutuhan penelitian, serta agar diperoleh hasil penelitian dengan tingkat objektifitas yang tinggi.

\section{DAFTAR PUSTAKA}

Aziza, N., \& Nurcahyo, Y. E. (2017). Model Rancangan Pengukuran Kinerja dengan Pendekatan Metode Integrated Performance Measurement System. Teknika: Engineering and Sains Journal, 1(1), 33-40.
Djojonegoro, W., \& Slamet. (1998). Pengembangan sumberdaya manusia melalui sekolah menengah kejuruan (SMK). Departemen Pendidikan dan Kebudayaan.

Kaplan, R. S., \& Norton, D. P. (2001). Strategyfocused organization: How balanced scorecard companies thrive in the new business environment/Robert $S$. Kaplan, David P. Norton.-Boston: Harvard Business School Press.

KURNIA, H. (2018). ANALISIS PENGUKURAN KINERJA SEKOLAH MENENGAH PERTAMA DA'WAH PEKANBARU MENGGUNAKAN METODE INTEGRATED PERFORMANCE MEASURMENT SYSTEM (IPMS). Universitas Islam Negeri Sultan Syarif Kasim Riau.

Wibowo, A. (2017). Manajemen pendidikan karakter di sekolah.

WIBOWO, S. P. (2018). USULAN PERBAIKAN KINERJA PERUSAHAAN (KPI) DENGAN MENGGUNAKAN METODE PERFORMANCE PRISM DAN METODE OMAX DI PT. GLOBALINDO INTIMATES KLATEN JAWA TENGAH.

Widodo, I., \& RAHARDJA, R. (2011). Analisis Kinerja Perusahaan dengan Menggunakan Pendekatan Balanced Scorecard (Studi Kasus Pada Perusahaan Mebel PT. Jansen Indonesia). Universitas Diponegoro.

Yani, D. (2019). PENGUKURAN KINERJA PERUSAHAAN MENGGUNAKAN INTEGRATED PERFORMANCE MEASUREMENT SYSTEMS (IPMS)(STUDI KASUS: PT. SEJAHTERA PANCA JAYA PEKANBARU). Universitas Islam Negeri Sultan Syarif Kasim Riau. 